\title{
Crónica EU Conference on the welfare of dogs and cats. Bruselas, 2013.
}

\author{
María González Lacabex ${ }^{1}$
}

Bajo el título "Building a Europe that cares for companion animals", el 28 de octubre de 2013 se celebró en Bruselas la primera conferencia europea sobre el bienestar de perros y gatos, organizada por la Comisión Europea y la Presidencia de Lituania con la colaboración del Eurogroup for Animals, la Federación de Veterinarios de Europa y Vier Pfoten International. Al evento acudieron más de 470 personas, en representación de autoridades, administraciones públicas, sectores económicos relacionados con este tipo de animales, profesionales diversos (Veterinaria, Derecho...) y particulares interesados.

La conferencia tiene como punto de partida el hecho de que actualmente existe en la Unión Europea una población estimada de más de cien millones de perros y gatos de compañía. El incremento del número de estos animales ha venido acompañado del progresivo desarrollo de toda una industria dirigida a su tenencia (cría, alimentación, salud, cosmética, accesorios...), y con ello de importantes problemáticas a las que hacer frente y sobre las que sin embargo no existe una regulación armonizada: mercado negro de cachorros criados en granjas con deficientes condiciones de bienestar, selección genética que favorece enfermedades o mutilaciones por condiciones estéticas, tráfico ilegal de animales con repercusiones no sólo comerciales sino también de sanidad animal y salud pública, o el abandono de perros y gatos como consecuencia de su reproducción incontrolada.

Tras la apertura por parte de representantes de la Comisión Europea y de la República de Lituania, y en la que no faltó la alusión - y reivindicación - expresa de la parlamentaria europea Marit Paulsen al concepto de la dignidad propia de todo animal (y no sólo de los animales de compañía), la Conferencia comenzó con una ponencia plenaria a cargo del Profesor James Serpell (Universidad de Pensilvania, EEUU) dirigida a contextualizar y explicar desde un punto de vista sociológico el fenómeno de la convivencia con animales de compañía, destacando su función de soporte social, emocional, instrumental, etc. en la sociedad actual.

\footnotetext{
${ }^{1}$ Abogada. Máster en Derecho del Medio Ambiente. Especialista Universitaria en Desarrollo Sostenible y Agenda 21 Local. Postgrado Animales, Derecho y Sociedad (UAB, 2011). Promotora de ANIMALEX, despacho dedicado exclusivamente a Derecho Animal.
} 
La primera sesión estuvo centrada en el análisis de la legislación actual sobre el bienestar de perros y gatos a nivel de la Unión Europea, limitada fundamentalmente a regular los movimientos de estos animales con fines de salud pública y sanidad animal. Tras el marco general europeo, se expusieron los modelos y experiencias de distintos países. Así, conocimos el enfoque de la nueva Ley de Protección y Bienestar Animal que entró en vigor el 1 de enero de 2013 en Lituania y que establece, entre otras, obligaciones concretas para los criadores de animales de compañía. Por su parte, el representante de Bélgica compartió la interesantísima experiencia de este país en materia de regulación y control del comercio de estos animales, cuya venta en tiendas o lugares públicos se encuentra prohibida desde 1996. Desde Italia se expuso el tratamiento del comercio ilegal de animales en el propio Código Penal y, por último, tuvo lugar la ponencia sobre la experiencia de Suiza, centrada en la necesidad de una tenencia responsable y la definición de los diversos niveles de formación legalmente exigidos en este país para dicha tenencia.

Tras el almuerzo de trabajo, la segunda sesión de la conferencia se desarrolló en torno a las problemáticas concretas derivadas de la cría y comercio de animales de compañía. A través de las ponencias integradas en esta segunda sesión se aportaron las perspectivas y puntos de vista de la protección animal, de la Veterinaria, del Derecho y de los mismos propietarios. Desde sus diversos enfoques, todos los ponentes coincidieron reconocer y destacar las consecuencias negativas que, tanto en términos de bienestar animal como de interés humano (salud pública, derechos de los consumidores), están teniendo efectivamente en la actualidad la cría, el transporte y el comercio no controlados de animales de compañía.

Con la tercera sesión, moderada por Andrea Gavinelli, diversos agentes implicados compartieron sus posicionamientos y propuestas para hacer frente a las problemáticas señaladas a lo largo de la jornada. En este bloque de ponencias, junto a representantes de la industria de alimentación de animales de compañía, de la federación cinológica internacional y del sector de transporte de animales, entre otros, la representante de Vier Pfoten Marlene Wartenberg expuso su propuesta de intervención multisectorial y multiagente como estrategia para abordar proyectos concretos en esta materia.

El cierre de la Conferencia tuvo como uno de sus puntos principales la reflexión sobre el papel que la Comisión Europea está llamada a desempeñar en esta materia. En este sentido, la representación europea quiso trasladar su convicción de que puede existir una base competencial y, por tanto, margen de actuación suficiente en este ámbito por parte de la UE. Sin embargo, también se quiso llamar la atención sobre la necesidad de determinar precisamente cuál ha de ser esa base legal que justifique la actuación comunitaria, como primer e ineludible paso. Se insistió en los principios de atribución, subsidiariedad y proporcionalidad que deben orientar en todo caso la 
intervención de la Unión Europea. Se trata, en definitiva, de identificar una clara necesidad de actuación para después definir el valor añadido que frente a la misma puede aportar la UE.

Con este objetivo, se anunció que la primera medida a adoptar por la UE será el desarrollo de un estudio sobre el bienestar de perros y gatos implicados en prácticas comerciales. A partir de los resultados de dicho estudio (cuya finalización se prevé para diciembre de 2014) y de esta misma conferencia, la Comisión Europea considerará la procedencia de establecer medidas de carácter comunitario dirigidas a combatir las problemáticas apuntadas. En cualquier caso, sí se adelantó que existen determinados ámbitos a los que se piensa que esta Comisión podría contribuir directamente, como por ejemplo en los sistemas de identificación y registro de animales: una herramienta básica en materia de protección animal, prevención del abandono, control de la salud pública... y sobre la que la Comisión Europea tiene una demostrada experiencia y capacidad que poner al servicio de los Estados miembros.

Para finalizar la jornada, las y los asistentes pudimos continuar debatiendo e intercambiando experiencias y opiniones en una cena de trabajo por cortesía de Vier Pfoten. Con ella se puso fin a esta interesante y enriquecedora conferencia que esperamos constituya, efectivamente, el punto de partida para una Unión Europea comprometida e implicada - también - con los perros y gatos con los que convivimos.

Más información 